\title{
Cultura de paz, moralidade e virtudes cívicas: Contribuições da psicologia cultural
}

\author{
Culture of peace, morality and civic virtues: cultural psychology contributions
}

Letícia de Sousa Moreira ${ }^{[a]}$, Angela Uchoa Branco ${ }^{[b]}$

\footnotetext{
${ }^{[a]}$ Mestranda do Programa de Pós-Graduação em Processos de Desenvolvimento Humano e Saúde, da Universidade de Brasília, (UnB), Brasília, DF - Brasil, e-mail: leticia_psi@hotmail.com.

${ }^{[b]}$ Docente da Universidade de Brasília, Brasília, DF - Brasil, e-mail: ambranco@terra.com.br
}

Recebido: 05/04/2011 Received: 04/05/2011

Aprovado: 21/07/2011 Approved: 07/21/2011

\section{Resumo}

Este artigo traz uma reflexão teórica acerca da construção da Cultura de Paz, a partir da interdependência de fatores culturais e psicológicos como moralidade e virtudes cívicas. A partir da perspectiva sociocultural construtivista, argumentamos que as significações e as interações sociais típicas de um contexto cultural específico resultam em uma unidade inseparável, e os processos de significação mediados pela comunicação, na cultura, adquirem um papel constitutivo da cidadania. Nesse sentido, a ação moral e ética envolve a justiça, e a cidadania resulta de uma relação coerente entre o individual e o coletivo, que irá permitir a aproximação entre julgamento, ações e interações morais necessárias à construção da cidadania e da paz. Ações orientadas pelo princípio de justiça, pela cooperação e solidariedade consolidam a ideia de que as interações humanas podem ser geradoras da paz e serem desenvolvidas a partir de práticas proativas que dependem tanto dos sujeitos quanto das sociedades envolvidas no processo. Entende-se que motivação e ações pró-sociais estão profundamente relacionadas à ética (normas coletivas) e à moralidade (princípios pessoais), e podem surgir com base em reflexões conscientes aplicadas à transformação individual, e orientadas para a construção e vivência de práticas fundamentais para promover uma Cultura de Paz nos vários contextos de desenvolvimento humano.

Palavras-chave: Cultura de paz. Valores. Desenvolvimento moral. Virtudes.

\section{Abstract}

This article offers a theoretical appraisal about the construction of a Culture of Peace, taking into account the interdependence of cultural and psychological factors such as morality and civic virtues. From a constructivist sociocultural perspective, we explain that the meanings and the social interactions typical of a certain cultural context consist of an integrated unity, and that processes of meaning mediated by communication, within cultural contexts, perform a fundamental role building citizenship. In this sense, moral and ethical actions involve justice, and citizenship results from building coherence between individual and collective stances. This allows for bringing together moral judgments, actions and interactions necessary for constructing citizenship and peace. Actions oriented by principles of justice, co-operation and solidarity consolidate the idea 
that human interactions may generate peace, interactions which may be developed by pro-active practices which, in turn, are only put forward by the involvement of both individuals and societies. Motivation and pro-social actions are intimately related to ethics (collective norms) and morality (personal principles), and can result from concious reflections related to personal transformations, leading to the construction of fundamental practices guided to promote a Culture of Peace within the various contexts of human development.

Keywords: Culture of peace. Values. Moral development. Virtues.

Compreender, refletir e gerar conhecimentos sobre o ser humano envolve o estudo de toda uma gama de fatores que se entrelaçam. Uma configuração social onde as pessoas possam interagir no contexto de práticas cooperativas e construtivas, entretanto demanda analisar o modo pelo qual aspectos como cultura, valores, moralidade e ética. Tais fatores mediam o comportamento humano e as interações sociais, que vão se constituindo mediante os processos de socialização na família, na escola, e nos mais variados setores da sociedade (Galán, 2005; Milani, 2003; Ratner, 2002).

A construção de uma Cultura de Paz (Jares, 2002) está intrinsecamente relacionada à resolução não-violenta dos conflitos. É uma cultura baseada em tolerância, solidariedade e compartilhamento em base cotidiana; uma cultura que respeita os direitos individuais, o princípio da diversidade e do pluralismo, e que assegura e sustenta a liberdade de opinião. A Cultura da Paz é uma cultura positiva, e não pode ser definida pela simples ausência ou prevenção, da violência, e não se empenha a promover o conformismo entre as pessoas. Na verdade, ela implica que os conflitos e divergências necessários ao jogo democrático ocorram mediante negociações construtivas, impedindo assim conflitos violentos, os quais devem ser evitados e resolvidos de forma eficaz, porém, alternativa. Está, assim, diretamente relacionada com a cidadania.

A partir desses pressupostos, o presente artigo faz reflexões teóricas acerca da importância da cultura, dos valores sociais, da moralidade, ética e virtudes cívicas para a construção da Cultura de Paz nos diversos seguimentos da sociedade, com o intuito de promover o desenvolvimento humano e a educação formal e informal no sentido da paz e da solidariedade (Baggio, 2009).

\section{Cultura e desenvolvimento humano: fundamentos da psicologia cultural}

A sociedade contemporânea apresenta uma configuração sociocultural bastante diversificada, em que crenças e valores plurais criam e são criados continuamente pelos múltiplos contextos em que a pessoa está inserida. 0 desenvolvimento humano ocorre de maneira diferenciada para cada pessoa, apesar de que gerações específicas compartilhem práticas e valores semelhantes. Esse desenvolvimento é fruto da interação de uma série de fatores, em especial do contexto sócio-histórico-cultural em que a pessoa está inserida, e as relações que esta estabelece nesses contextos ao longo de sua vida.

Com base em estudos antropológicos, Geertz (1989, p. 15) define o conceito de cultura como essencialmente semiótico. Acredita que o homem é um animal amarrado a teias de significados que ele mesmo teceu, e assume o estudo da cultura, não como uma ciência experimental em busca de leis, mas como uma ciência interpretativa à procura de significados. Afirma: "É justamente uma explicação que eu procuro, ao construir expressões sociais enigmáticas em sua superfície".

Ressaltando a importância da cultura, Bruner $(1997$, p. 22) relata que "o divisor na evolução humana foi cruzado quando a cultura se tornou o fator principal para dar forma às mentes daqueles que viviam sob sua influência". Sendo assim, a participação do homem na cultura, e a realização de seus processos mentais por meio dela, são imprescindíveis para seu desenvolvimento. 0 referido autor afirma que a psicologia cultural não está focada em comportamentos, mas em ações situadas e significadas dentro de um cenário cultural, e as intenções dos participantes são de grande importância. Nessa orientação, dizer e fazer constituem uma unidade inseparável, 
pois os processos de significação mediados pela cultura tornam-se públicos quando compartilhados. 0 autor coloca, ainda, que viver em sociedade é compartilhar interpretações e significados de forma pública para manter e permitir o desenvolvimento da própria cultura e daqueles que a constituem.

Segundo Vygotsky (1989), o ser humano se constitui sócio-historicamente por meio de um processo no qual a cultura é parte essencial da construção das funções psicológicas superiores. Para o autor, tais funções manifestam-se primeiramente no nível das interações sociais, para depois tornarem-se funções psicológicas superiores, internas e individuais. Em uma perspectiva dialógica, cada vez mais assumida no campo da Psicologia (Salgado \& Gonçalves, 2007; Valsiner, 2007), o indivíduo transforma e é transformado pelo seu contexto cultural de forma simultânea.

A partir da perspectiva de Vygotsky, muitos autores vêm realizando pesquisas sobre o desenvolvimento humano e a sociocultura. Valsiner (1989, 1998, 2007) e Bronfenbrenner (1989), grandes teóricos desta área, definem o desenvolvimento como processo de transformação ao longo da irreversibilidade do tempo. Na visão de Bronfenbrenner, ocorrem mudanças em nível estrutural-funcional baseadas nas contínuas interações do organismo com seu meio ambiente. Para Valsiner, sujeito e cultura se constituem e se desenvolvem mutuamente, de acordo com processos bidirecionais. Sob certas condições o organismo sofre mudanças que o levam para um novo patamar qualitativamente diferente, e suas experiências abrem novas possibilidades de desenvolvimento em múltiplas trajetórias. Autores que destacam o papel da cultura (Bruner, 1997; Cole, 1992; Valsiner, 2007) ainda argumentam que é no contexto das interações sociais que se criam e se negociam os significados e valores socioculturais transformados pela pessoa em desenvolvimento, os quais movimentam tanto o sujeito, quanto a sociedade.

Segundo Branco e Valsiner (1997), a psicologia cultural, em sua versão sociocultural construtivista, enfatiza a origem social da ontogênese psicológica humana (sociogênese), mas também afirma a importância do sujeito como agente ativo de seu desenvolvimento, como sempre afirmou Piaget (1994). Na perspectiva sociocultural construtivista, o meio ambiente social não "modela" o desenvolvimento do ser humano, mas provê os recursos de regulação e suporte para a construção da individualidade pessoal, do sistema de self.
Valsiner (2007) aponta, ainda, que a noção de sociedade é uma construção social relativamente recente, constituindo o significado da intersecção dos domínios públicos e privados da existência humana. Assim, as interações entre indivíduo e sociedade se constroem e vão assumindo diferentes significados, os quais são permanentemente negociados em diferentes instâncias. Em seus estudos, Valsiner enfatiza que as ações sociais funcionam como mediador semiótico nos processos de desenvolvimento humano e têm fundamental papel para a transformação de pessoas e instituições. Contextos e sujeito ativo, mediante processos de internalização/externalização de mensagens culturais, acabam gerando reguladores externos e também intrapsíquicos para o desenvolvimento humano no que se refere à construção de valores, crenças, práticas e tradições.

Com base na ideia de que o ser humano está em constante desenvolvimento, Rogoff (2005, p. 51) concebe o desenvolvimento como a transformação da participação das pessoas em atividades socioculturais contínuas que se modificam com o envolvimento de indivíduos em cada fase de seu processo pessoal de desenvolvimento (ontogênese), e também em sucessivas gerações. A autora afirma que, na perspectiva sociocultural:

[...] a cultura não é uma entidade que influencia os indivíduos. Em lugar disso, as pessoas contribuem para a criação de processos culturais e estes contribuem para a criação de pessoas. Dessa forma, os processos individuais e culturais são mutuamente constitutivos e não definidos separadamente.

Rogoff $(2005$, p. 50) refere-se à teoria histórico-cultural de Vygotsky, argumentando que "os esforços individuais não são separados dos tipos de atividades nos quais as pessoas se envolvem e dos tipos de instituições de que fazem parte". Entende, assim, que o desenvolvimento humano precisa ser estudado a partir de uma visão multifacetada, envolvendo todas as dimensões da pessoa e os papéis que desempenha em seu contexto sociocultural. Pensar aqui as práticas institucionais e a modalidade de participação dos membros da instituição social pode, portanto, ser um caminho produtivo para implementar transformação e desenvolvimento, seja em nível pessoal, como institucional e social, tema de nosso interesse no contexto do presente trabalho. 
Branco (2006) ressalta que a cultura coletiva é importante para o desenvolvimento do sistema de valores e crenças do ser humano, pois estes promovem certas formas de conduta social. Também Valsiner (2007) postula que os significados compartilhados da cultura coletiva, entre eles normas e regras sociais, acabam por conduzir as práticas sociais diárias. A cultura pessoal, para ele, é constituída pelos significados que cada indivíduo internaliza e que regem seu comportamento, crenças e valores. Na visão do autor, essas duas formas de cultura - individual e coletiva -interagem dialeticamente proporcionando o desenvolvimento e a relativa adaptação do indivíduo ao seu contexto sociocultural.

De acordo com Sifuentes, Dessen e Lopes de Oliveira (2007), a participação do indivíduo na construção do mundo social possibilita a emergência de diferentes significações, que podem transformar o curso de seu desenvolvimento, assim como afetar a dinâmica do meio sociocultural em que está inserido. Por outro lado, as autoras concordam com os estudos de Valsiner (2003), postulando que as práticas sociais afetam as significações e construções simbólicas da pessoa em uma relação bidirecional.

\section{Desenvolvimento moral e ético}

As questões inerentes à moralidade têm sido alvo de estudiosos de diversas áreas ao longo da história, como na Filosofia, Teologia, Antropologia e, mais recentemente, a Psicologia tem destinado especial atenção ao tema, inicialmente com os trabalhos de Piaget e Kohlberg sobre a questão (Lourenço, 1998). $\mathrm{O}$ interesse pela moralidade se intensificou graças a sua natureza social e função reguladora que exerce no convívio entre os seres humanos, constituindo um constructo sociocultural elaborado de acordo com os interesses dos diversos grupos (Barrios \& Branco, 2008; Lapsley \& Narvaez, 2004).

Freitag (1997, p. 268), ao estudar a problemática da moralidade e da ética, ressalta que as diferentes teorias sobre o assunto de certa forma se relacionam constituindo um campo de reflexão comum às três orientações: filosófica, sociológica e psicológica. A questão da moralidade abordada pela tragédia grega que nomeia o livro da autora (Itinerários de Antígona) deixa claro que as ações morais são irreversíveis. "Não há como voltar atrás, fazendo de conta que nada aconteceu". Segundo a narrativa da tragédia de Sófocles, ocorre um dilema ético/moral, e a personagem decide arriscar sua vida para seguir seus preceitos pessoais vinculados à tradição familiar, em contraposição à norma ética da coletividade. Ou seja, "optar por uma ou outra orientação significa sempre optar por uma trajetória em detrimento de outra, implicando outros objetivos intencionados e efeitos colaterais não desejados". Portanto, sempre que houver um dilema moral envolvido, haverá uma perda que precisa ser compreendida e aceita. Segundo a autora, o conceito de moral se aproxima mais do aspecto do indivíduo, enquanto ética se relaciona com o aspecto social, coletivo. Mas, na verdade, moral e ética são dimensões profundamente relacionadas de um mesmo fenômeno.

Segundo Martins e Branco (2001, p. 170), o desenvolvimento moral necessita de "um modelo aberto, que contemple a natureza dinâmica, plural, complexa e co-construída do desenvolvimento, onde os caminhos do processo nunca podem ser determinados previamente com exatidão". Propõem também que o estudo do desenvolvimento moral deve contemplar o caráter dialógico e o fluxo constante que caracterizam a realidade social e psicológica da investigação. Ou seja, os conceitos morais e éticos que atuam na vida cotidiana das pessoas passam, necessariamente, por um crivo social. Lustosa (2005) compartilha essa ideia e enfatiza a importância do desenvolvimento moral para o entendimento do desenvolvimento integral do ser humano. Tais reflexões ampliam as possibilidades de discussão sobre o tema, partindo do princípio que os conceitos morais e éticos não são estáticos, mas podem ser (re)construídos a qualquer momento dependendo da motivação pessoal.

Barrios e Branco (2008, p. 415) afirmam que:

[...] a existência de preceitos obrigatórios no código moral de diferentes comunidades não deve ser entendida como a existência de valores morais universais e abstratos desvinculados da realidade. Tais valores são compartilhados pelas diferentes culturas em função de sua importância para o convívio constitutivo dos seres humanos nos contextos sociais.

Entende-se, a partir dessa ideia, que o desenvolvimento moral ocorre em um processo histórico de constituição mútua entre indivíduo e sociedade, de forma concomitante. Os valores morais vão sendo construídos pela pessoa em interação com seu contexto sociocultural que, em nível macro, também vai sendo transformado pela interação com as pessoas que nele se inserem e com outras culturas. 
Shweder e Much (1987) propõem que as crenças morais têm sua origem ontogenética nas mensagens e significados implicitamente transmitidos a partir da fala, da conversação, do discurso e da prática cotidiana. Sugerem que em cada cultura os julgamentos morais que são comuns são aprendidos por razões específicas e fazem sentido para aquele grupo, ao passo que os julgamentos morais que são distintos de cada cultura, existem porque fazem sentido apenas para determinados contextos. A partir dessa ideia, observa-se que os conceitos morais devem ser analisados com base em uma análise semiótica abrangente e ampliada, que contemple a vida social do indivíduo.

A ação moral está, pois, relacionada com a motivação pessoal para o exercício da moralidade, e é contextualizada e transversalizada por uma cultura, onde os princípios, ideais e julgamentos são formados. A partir do contínuo processo de construção e desenvolvimento moral, os conceitos saem do nível do discurso para a ação, transformando as pessoas em cidadãos comprometidos, ou não, consigo mesmos e com a coletividade.

Tognetta e La Taille (2008, p. 182), concordando com Ricoeur, dizem que a definição de ética nos permite compreender sua amplitude: "uma vida boa, em termos éticos, é consequência de um sentido de felicidade que contemple o si mesmo e também o outro e completa-se em instituições em que um conteúdo moral esteja presente: a justiça". Dessa forma, agir moral e eticamente envolve ser justo consigo e com os outros, construindo uma relação coerente com o coletivo. Assim, alguns princípios éticos teriam aspectos universais e, nessa direção, vale ressaltar a íntima relação entre moral, ética, valores e virtudes.

\section{Valores sociais e virtudes}

O mundo contemporâneo tem retomado discussões e reflexões sobre os valores sociais e as virtudes na sociedade. Isso demonstra uma preocupação eminente com as pessoas, suas ações e comportamentos no mundo moderno, onde o que se percebe é justamente o contrário: a falta de ética e a desvalorização das virtudes.

Os valores sociais se desenvolvem à medida que o próprio processo de socialização acontece, implicando diferenças consideráveis de pessoa para pessoa. Barrios e Branco (2008) apontam que a existência de valores éticos e morais compartilhados por diferentes culturas não significa a existência de uma moralidade única e homogênea para os diferentes sistemas sociais que coexistem em um determinado momento da história da humanidade, mas se deve à origem e ao desenvolvimento filogenético do ser humano. Viver em grupo, em sociedade, exige a adoção de normas mínimas de convivência No entanto, cada cultura apresenta também valores morais muito peculiares, e cada pessoa vive um processo individual de inserção cultural no curso de sua ontogênese.

Staub (2003) sugere que os valores sociais - que certamente incluem os valores morais - encontram-se dinamicamente organizados e hierarquicamente integrados no sistema motivacional da pessoa, aí incluindo outros elementos tais como, por exemplo, orientações para objetivos pessoais, necessidades, preferências e motivos, bem como formas internalizadas de normas, regras e hábitos específicos da cultura. Os valores sociais representam, para este autor, importante parte do sistema complexo da motivação social, pois os valores tendem a orientar e promover comportamentos e interações específicos ao longo do processo de socialização. De acordo com ele, por exemplo, a motivação pró-social tende a gerar comportamentos pró-sociais que visam beneficiar outras pessoas; ao contrário, a hostilidade, como motivação social recorrente, acaba por promover a agressão.

No sentido de promover uma espécie de consenso ético entre as complexas sociedades modernas, Maturana e Varella (1995, p. 23) ressaltam dois poderosos recursos, de qualidade universal:

1) 0 altruísmo biológico natural e a necessidade do ser humano em fazer parte de grupos e trabalhar em consenso com eles.

2) 0 poder de transformação da reflexão consciente.

Os autores afirmam que sem altruísmo não há fenômeno social e defendem que "é em tal expressão de nossa natureza social que radica a esperança de nos tornarmos verdadeiramente humanos, com toda a carga ética que essa expressão implica". Para eles, é na reflexão e no exercício dos valores sociais, como o altruísmo, que o ser humano poderá se abrir para espaços de coexistência e buscar a cooperação. Acrescentamos, e assim construir uma cultura de Paz. 
Palmieri e Branco (2004) apontam que estudos têm sido realizados para investigar a ocorrência de comportamentos caracterizados como pró ou antissociais. De uma forma geral, a maioria dos autores por elas pesquisados concorda que os comportamentos pró-sociais são aqueles que representam ações ou atividades consideradas como socialmente positivas, visando atender às necessidades e ao bem-estar de outras pessoas, como, por exemplo, o altruísmo, a generosidade, a cooperação, os sentimentos de empatia e simpatia etc. Já Eisenberg, Fabes e Spinrad (2006) apontam as diferentes modalidades do comportamento pró-social, que inclui tanto ações altruístas, como ações motivadas por interesses específicos por parte daquele que beneficia o outro social. Destacam que no altruísmo existe a presença de um elemento motivacional interno, isto é, o indivíduo é motivado a atuar de forma voluntária visando ao benefício de outras pessoas, sem a perspectiva aparente de ganhos pessoais, à exceção da autorrecompensa.

Branco (2003, p. 182), em seus estudos sobre cooperação, a define como "ação ou trabalho conjunto com outros em busca de um objetivo comum". A autora enfatiza que a cooperação é uma forma de trabalho onde todos se beneficiam e se desenvolvem mutuamente. Palmieri e Branco (2004) destacam, por sua vez, que comportamentos pró-sociais podem incluir a cooperação, mas muitos são especialmente voltados para atender às necessidades e ao bem-estar de outras pessoas, como, por exemplo, o altruísmo, a generosidade, a ajuda, e os sentimentos de empatia e simpatia. A motivação para tais comportamentos, no entanto, é continuamente estimulada ou reprimida por sugestões e práticas culturais.

Conceitos como cooperação e ajuda, assim, consolidam a ideia de que ações e interações voltadas para a paz podem ser desenvolvidas e dependem tanto dos sujeitos quanto das sociedades envolvidas no processo. Motivação e ações pró-sociais estão profundamente relacionadas à ética (normas coletivas) e à moralidade (princípios pessoais), e podem surgir com base em reflexões conscientes aplicadas à transformação individual, orientadas para a construção e vivência de práticas pró-sociais fundamentais para a construção de uma Cultura de Paz. Princípios como justiça e solidariedade teriam, assim, um caráter de necessária universalidade na promoção da paz.
Nesse sentido, a proposta de Galán (2005) e colaboradores, apresentada sob a forma de livro intitulado "Democracia y virtudes cívicas", apresenta, discute e ressalta a importância das virtudes individuais no desempenho das atividades coletivas. Camps (2005), por exemplo, enfatiza que a sociedade atual democrática e liberal necessita de pessoas virtuosas tanto quanto necessitava a sociedade grega. A ideia de conseguir excelência na atividade humana - núcleo do conceito de virtude - tem sido explorada em vários setores da vida, sendo mais enfatizada e exigida no mundo profissional. Entretanto, a Psicologia pouco tem se dedicado a esta questão no que tange à vida e ao desenvolvimento humano para além da profissão.

Segundo Camps (2005, p. 23), a virtude pública nasce com a definição aristotélica de homem como um animal político, dotado de razão, e que discute e toma decisões com sua comunidade. Pensar em uma comunidade específica e previamente formada, reforçada por evidentes marcas e traços culturais e orientada para uma convivência cidadã irá facilitar a construção de uma identidade moral que permite o viver juntos sem que haja mútua destruição. "O indivíduo que se propõe a ser verdadeiramente humano, que transforma a comunidade em que vive, sua profissão ou funções que exerce na comunidade, merece ser chamado de ético".

A autora afirma, ainda, que Aristóteles articulou sua teoria em torno de uma virtude central, a capacidade de ser justo em cada momento, e a sabedoria para decidir o que é mais adequado em cada situação. Nessa visão, a virtude da prudência, tão destacada pelo filósofo grego, está sendo cada vez mais necessária em nossa sociedade. Constata-se que sua demanda é crescente, sobretudo no mundo profissional, onde os exageros têm se tornado fonte de preocupação.

Galán (2005, p. 191), por sua vez, reafirma a necessidade de virtudes públicas, enfatizando que a luta pela tolerância tem sido paralela à conquista da liberdade no mundo moderno. Ou seja, à medida que o ser humano conquista a liberdade para agir, também deveria adquirir tolerância para com os outros e responsabilidade por suas ações, promovendo a paz. $\mathrm{O}$ autor cita a famosa frase de Voltaire "a tolerância é patrimônio da humanidade" e compartilha a ideia, afirmando que essa é uma virtude primordial para o ser humano como ser necessariamente social. 
A Unesco (1995, p. 11), por meio da Declaração Mundial dos Princípios sobre a Tolerância, ressalta que um dos caminhos para a paz é a tolerância e que ela deve transformar as diferenças em harmonia, em qualquer contexto. "A tolerância é, antes de tudo, uma atitude ativa fundada no reconhecimento dos direitos universais da pessoa humana e das liberdades fundamentais do outro". Por isso a tolerância deve ser compreendida como "um princípio e uma virtude que torna a paz possível e contribui para substituir uma cultura de guerra por uma cultura de paz". Assim, a tolerância trabalha no sentido de que os seres humanos tenham o direito de viver em paz, e de serem como são, assumindo a diversidade em pacífica convivência.

Valcárcel (2005) concorda com essa ideia e enfatiza que a liberdade e a igualdade são dois dos valores básicos de nossa convivência política e dos princípios articuladores da ética atual. Postula que a liberdade foi acompanhada por sua nova correspondente nas virtudes cívicas, a tolerância. Na mesma direção, Vallespín (2005) defende que a justiça é a virtude política por excelência, sendo um atributo tanto da pessoa quanto de sua comunidade. Ele também ressalta que as diferentes concepções de caráter moral que são atribuídas à categoria de 'justo' dependem de uma decisão prévia a respeito do que tem valor, do que merece aprovação moral no campo da ação social em um dado contexto. Para ele, a justiça pressupõe as ideias de equidade e imparcialidade na divisão social e do trabalho, ou seja, considerar as necessidades individuais para buscar soluções justas para todos.

Vargas-Machuca (2005) concebe a solidariedade em termos morais como uma virtude moral que completa a justiça. Considera a solidariedade como uma das expressões da ação coletiva, particularmente aquela que remete ao interesse dos indivíduos pela promoção de bens públicos ou pelo bem-estar dos outros. A solidariedade moral não se associa a identificação mútua, nem a um sentido de pertença e nem reciprocidade, se não que funda o reconhecimento, o respeito e a consideração que a pessoa deve aos outros nessa forma primordial do argumento moral que exige se imaginar a si próprio na situação de outras pessoas.

A ideia de virtude pública também engloba os valores e crenças transformados em ação. Os valores, assim como as virtudes, ajudam o ser humano a ser livre, e cada ação individual virtuosa acaba por refletir na melhoria da vida coletiva. Camps (2005, p. 31) reforça essa ideia dizendo que "a moral e as virtudes são uma tarefa individual, mas sua função é pública". Na perspectiva da psicologia cultural, entretanto, cabe também, e em especial, às instituições promotoras das práticas sociais favorecerem o desenvolvimento de virtudes cívicas, essenciais à construção de uma Cultura de Paz. Concordamos, porém, com a autora que as virtudes cívicas são necessárias ao bom relacionamento no contexto sociocultural, sendo assim fundamental à promoção da paz.

\section{Cultura de paz}

De acordo com Jares (2002, p. 131), a paz deve ser entendida como "um fenômeno amplo e complexo que exige uma compreensão multidimensional". Partindo-se do pressuposto que o conceito de paz adquire diferentes significados nos diferentes contextos socioculturais, somente a partir da adoção de uma visão ampla será possível melhor compreender a paz em seus processos e resultados.

Segundo o Ministério da Saúde (2009), a paz é um fenômeno complexo que envolve a construção de uma estrutura social e de relações sociais em que exista justiça, igualdade, respeito, liberdade, e que seja caracterizada pela ausência de todo o tipo de violência. Está relacionada ao desenvolvimento, aos direitos humanos, à diversidade e à cooperação entre pessoas, grupos ou nações. Na visão de Jares (2002) e Dusi (2006), a paz é reconhecida não somente como a ausência de conflitos, mas como um processo positivo, dinâmico e participativo em que se promove o diálogo e a resolução de conflitos em um espírito de cooperação. Dessa forma, a paz envolve uma visão de processos em construção, ação e investimento pessoal e coletivo, que pode modificar as pessoas e o mundo à sua volta por meio das interações concretas entre as pessoas.

Jares (2002) reafirma que a paz se refere a uma estrutura e a relações sociais caracterizadas não só pela ausência de todo tipo de violência, mas pela presença da justiça, da igualdade, do respeito e da liberdade, valores humanistas reconhecidos na Declaração dos Direitos Humanos das Nações Unidas.

AOrganização das Nações Unidas - ONU (2000) lançou no ano 2000 um documento chamado "Manifesto 2000". Este definiu Cultura da Paz como um conjunto de valores, atitudes, tradições, comportamentos e 
estilos de vida de pessoas, grupos e nações baseados no respeito pleno à vida e na promoção dos direitos humanos e das liberdades fundamentais, na prática da não-violência por meio da educação, do diálogo e da cooperação, podendo ser uma estratégia política para a transformação da realidade social. Ao assinar o manifesto, as nações comprometem-se a, com os valores da paz, da tolerância e da solidariedade, converter em realidade cotidiana os valores, as atitudes e os comportamentos que inspiram a Cultura de Paz.

Segundo Milani (2003), um cidadão "da paz" transcende a visão de um indivíduo não violento. A paz é construída nas ações e interações cotidianas, envolvendo os mais diversos tipos de relações, caracterizando um movimento que é ampliado à promoção da "cultura de paz". Na visão deste autor, construir uma Cultura de Paz é promover as transformações necessárias e indispensáveis para que a paz seja o princípio governante de todas as relações humanas e sociais. Para tanto, define dois níveis básicos de ações: micro e macro. 0 primeiro refere-se ao indivíduo, seu comportamento, suas relações, sua vida cotidiana, trabalho, família, e todas as ações que podem ser construídas individualmente. 0 segundo refere-se ao coletivo, aos processos sociais, às mudanças estruturais, políticas públicas, programas educativos, buscando integrá-los à dinâmica social. Os dois níveis são interdependentes e precisam ser desenvolvidos concomitantemente.

A cultura de paz constitui-se, portanto, em um processo dinâmico que ocorre de forma individual e coletiva, buscando transformar as mais diversas sociedades. De acordo com a perspectiva sociocultural construtivista da psicologia cultural, o contexto sociocultural em que a pessoa está inserida atua de forma fundamental na construção dos mais diversos conceitos, valores e padrões de interação (Branco, 2006; Rogoff, 2005; Valsiner, 2007), podendo gerar sujeitos agressivos ou pacíficos, a depender da prevalência de práticas violentas, ou de cooperação, entre as pessoas. Em outras palavras, um contexto cultural que valorize a paz de forma concreta tende a gerar pessoas comprometidas com a paz, e vice-versa (Milani \& Branco, 2004). Isto porque o conceito de "paz" não pode ser visto apenas do ponto de vista teórico, ou ideal, mas deve ser analisado em termos das práticas culturais concretas para a resolução de problemas, que levam a ações específicas. Pode-se afirmar que as ações que buscam construir e manter a paz, nos mais diversos contextos são, sim, passíveis de serem desenvolvidas, saindo do plano das intenções para o plano das ações concretas.

A Unesco (1991, p. 6) tem agido sempre de acordo com os princípios delineados no preâmbulo de seu Ato Constitutivo e reafirma a ideia de que: "uma vez que as guerras começam na mente dos homens, é na mente dos homens que as defesas da paz devem ser construídas". Nesse sentido, a Cultura de Paz pode ser pensada como uma filosofia de vida. Essa ideia é compartilhada por Callado (2004), que a caracteriza como a busca coletiva de um modo de vida que contribua para a construção de um mundo marcado pela justiça, solidariedade e paz. Essa busca procura resolver os problemas por meio do diálogo, da negociação e da mediação, de forma a minimizar a violência e favorecer a cooperação e o entendimento (Senna, 2007).

A passagem da cultura da violência para uma Cultura de Paz exige desconstruir a legitimidade do uso da violência como instrumento de resolução de conflitos. Melman, Ciliberti, Aoki, e Figueira Jr. (2009) concordam que é preciso reconhecer a violência como algo que fere a dignidade humana, tanto da vítima quanto do agressor. Ou seja, todos acabam sendo prejudicados de alguma forma. Assim como a presença da violência na vida cotidiana é algo real, também é possível compreender que existem outras escolhas e que os impasses podem ser superados por meio do diálogo e da negociação (Bohm, 2005).

Em resumo, a Cultura de Paz está intrinsecamente relacionada à prevenção e à resolução não violenta dos conflitos. É uma cultura baseada em tolerância, solidariedade e compartilhamento em base cotidiana, uma cultura que respeita os direitos individuais e a diversidade, o princípio do pluralismo, que assegura e sustenta a liberdade de opinião. Ela se empenha em prevenir conflitos resolvendo-os em suas fontes ou origens. A construção da Cultura de Paz não é apenas viável, mas possível e necessária para fomentar pessoas melhores e, consequentemente, sociedades melhores (Jares, 2002).

\section{Considerações finais}

A cultura, os valores sócio-morais e a ética foram e continuam sendo alvo de intensas discussões nas 
Ciências Humanas e Sociais, por estarem diretamente relacionados à constituição do ser humano e sua presença no mundo. Atualmente, estes valores estão cada vez mais confusos, oscilantes e difíceis de serem identificados graças a vários fatores, especialmente pela evolução tecnológica e a miscigenação cultural. Estudar e discutir tal tema torna-se, portanto, relevante e necessário para o desenvolvimento do ser humano e da sociedade em geral. O desenvolvimento humano é contínuo e dinâmico, bem como a elaboração e vivência do conceito de paz, e tais características favorecem as transformações individuais e coletivas, rumo ao ideal de melhoria da qualidade da vida.

Nesse artigo, buscou-se refletir sobre a construção da Cultura de Paz, considerando aspectos que permeiam o desenvolvimento do ser humano como a cultura, moralidade e ética, e o importante papel das virtudes cívicas nos diferentes contextos sociais. A partir das concepções teóricas aqui analisadas, entende-se que o ser humano é capaz de desenvolver virtudes e valores morais que propiciem ações cooperativas e resultem em uma Cultura de Paz. Tal construção poderá, assim, resultar de uma intersecção dialética entre o indivíduo e a cultura, propiciando uma transformação paulatina que culmine em um movimento positivo e dinâmico para a resolução de conflitos e para a promoção de uma sociedade em paz.

\section{Referências}

Baggio, A. (2009). O princípio esquecido. São Paulo: Cidade Nova.

Barrios, A. M., \& Branco, A. U. (2008). Desenvolvimento moral: Novas perspectivas de análise. Psicologia Argumento, 25(51), 413-424.

Bohm, D. (2005). Diálogo: Comunicação e redes de convivência. São Paulo: Palas Athena.

Branco, A. U. (2003). Social development in cultural context: Cooperative and competitive interaction patterns in peer relations. In J. Valsiner \& K. Connolly (Org.). Handbook of developmental psychology (pp. 238-256). London: Sage.

Branco, A. U. (2006). Crenças e prática culturais: Coconstrução e ontogênese de valores sociais. Revista Pro-Posições, 17(50), 139-155.
Branco, A. U., \& Valsiner, J. (1997). Changing methodologies: A co-constructivist study of goal orientations in social interactions. Psychology \& Developing Societies, 9(1), 35-64.

Bruner, J. (1997). Atos de significação. Porto Alegre: Artmed.

Bronfenbrenner, U. (1989). Ecological systems theory. In R. Vasa (Org.). Annals of Child Development (pp. 187-249). Greenwich, CT: JAI Press.

Callado, C. V. (2004). Educação para a paz: Promovendo valores humanos na escola através da educação física e dos jogos cooperativos. São Paulo: Wak.

Camps, V. (2005). El concepto de virtud pública. In P. Galán (Org.). Democracia y virtudes cívicas (pp. 17-40). Madri: Biblioteca Nueva.

Cole, M. (1992). Culture in development. In M. H. Bornstein \& M. E. Lamb (Org.). Developmental psychology: An advanced textbook (pp. 731-788). Hillsdale: Lawrence Erlbaum Associates.

Dusi, M. M. (2006). A Construção da cultura de paz no contexto da instituição escolar. Dissertação de Mestrado, Universidade de Brasília, Brasília.

Eisenberg, N. Fabes, R., \& Spinrad, T. (2006). Prosocial development. In W. Damon, R. Lerner, \& N. Eisenberg (Org.). Handbook of child psychology (pp. 646718). Hoboken, NJ: Wiley.

Freitag, B. (1997). Itinerários de Antígona. Campinas: Papirus.

Galán, P. (2005). Democracia y virtudes cívicas. Madri: Biblioteca Nueva.

Geertz, C. (1989). A interpretação das culturas. Rio de Janeiro: LTC.

Jares, X. R. (2002). Educação para a paz: Sua teoria e sua prática. Porto Alegre: Artmed.

Lapsley, D.K. \& Narvaez, D. (2004). A social-cognitive approach to the moral personality. In K. Daniel, D. K. Lapsey, \& D. Narvaez (Org.). Moral development, self, and identity (pp. 189-212). Mahwah: Lawrence Erlbaum Associates.

Lourenço, O. (1998). Psicologia de desenvolvimento moral: Teoria, dados e implicações. Coimbra: Almedina. 
Lustosa, A. V. (2005). A compreensão da moralidade: contribuições teóricas da psicologia do desenvolvimento. In M. A. Dessen \& A. L. Costa Jr. (Org.). A ciência do desenvolvimento humano: Tendências atuais e perspectivas futuras (pp. 249-263). Porto Alegre: Artmed.

Martins, L., \& Branco. A. U. (2001). Desenvolvimento moral: Considerações teóricas a partir de uma perspectiva sociocultural construtivista. Psicologia: Teoria e Pesquisa, 17(2), 169-177.

Maturana, H., \& Varela, F. (1995). A árvore do conhecimento: As bases biológicas da compreensão humana. São Paulo: Pala Athenas.

Melman, J., Ciliberti, M. E., Aoki, M., \& Figueira Jr., N. (2009). Tecendo redes de paz. Saúde e Sociedade, 18(Suppl. 1), 66-72.

Ministério da Saúde (2009). Por uma Cultura da Paz, a promoção da saúde e prevenção da violência. Brasília: Ministério da Saúde.

Milani, F. M. (2003). Cultura de paz x violência. In F. M. Milani \& R. C. Jesus (Org.). Cultura de Paz: Estratégias, mapas e bússolas. Salvador: Inpaz.

Milani, F. M., \& Branco, A. U. (2004). Assessing Brazil's culture of peace. Peace and Conflict, 10(2), 161-174.

Organização das Nações Unidas - ONU. (2000). Manifesto 2000. Recuperado em 15 set. 2009, em http//:www. onu.org

Palmieri, M. W. A., \& Branco, A. U. (2004). Cooperação, competição e individualismo em uma perspectiva sócio-cultural construtivista. Psicologia: Reflexão e Crítica, 17(2), 189-198.

Piaget, J. (1994). 0 juízo moral na criança. São Paulo: Summus. (Publicação original em 1932)

Ratner, C. (2002). Cultural psychology: Theory and method. New York: Plenum.

Rogoff, B. (2005). A natureza cultural do desenvolvimento humano. Porto Alegre: Artmed.

Salgado. J., \& Gonçalves, M. (2007). The dialogical self: social, personal, and (un)councious. In J. Valsiner \& A. Rosa (Org.). Handbook of sociocultural psychology (pp. 608-621). Cambridge: Oxford University Press.

Senna, S. F. (2007). Protagonismo infantil e promoção da cultura de paz: Um estudo sociocultural construtivista. Tese de Doutorado, Universidade de Brasília, Brasília.
Shweder, R., \& Much, N. (1987). Determinations of meaning: Discourse and moral socialization. In W. Kurtines \& J. Gewirtz (Org.). Moral development through social interaction (pp. 197-244). New York: Wiley.

Sifuentes, T. R., Dessen, M. A., \& Lopes de Oliveira, M. C. (2007). Desenvolvimento humano: desafios para a compreensão das trajetórias probabilísticas. Psicologia Teoria e Pesquisa, 23(4), 379-385.

Staub, E. (2003). The psychology of good and evil: Why children, adults, and other groups help and harm others. New York: Cambridge University Press.

Tognetta, L. R., \& La Taille, Y. (2008). A formação de personalidades éticas: Representações de Si e Moral. Psicologia: Teoria e Pesquisa, 24(2), 181-188.

United Nations Educational, Scientific and Cultural Organization - UNESCO (1995). Declaração dos princípios sobre a tolerância. Recuperado em 15 set. 2009, em http://unesdoc.unesco.org

United Nations Educational, Scientific and Cultural Organization - UNESCO (1991). Ato constitutivo promulgado pelo Decreto n. 362. Brasília: República Federativa do Brasil.

Valsiner, J. (1989). Human development and culture: The social nature of personality and its study. Lexington: Lexington Books.

Valsiner, J. (1998). The guided mind: A sociogenetic approach to personality. Cambridge, MA: Harvard University Press.

Valsiner, J. (2003). Beyond social representations: A theory of enablement. Papers on Social Representations, 12, 1-16.

Valsiner, J. (2007). Culture in minds and societies: Foundations of cultural psychology. New York: Delhi Sage.

Vallespín, F. (2005). La justicia. In P. Galán (Org.). Democracia y virtudes cívicas (pp. 259-287). Madri: Biblioteca Nueva.

Valcárvel, A. (2005). Libertad e igualdad. In P. Galán (Org.). Democracia y virtudes cívicas (pp. 289309). Madri: Biblioteca Nueva.

Vargas-Machuca, R. (2005). Solidaridad. In P. Galán (Org.). Democracia y virtudes cívicas (pp. 311336). Madri: Biblioteca Nueva.

Vygotsky, L. (1989). Pensamento e linguagem. São Paulo: M. Fontes. 